\title{
Novel TIGR/MYOC mutations in families with juvenile onset primary open angle glaucoma
}

Diliana Stoilova, Anne Child, Glen Brice, Trushna Desai, Magda Barsoum-Homsy, Nusret Ozdemir, Line Chevrette, Marie F Adam, Henri-Jean Garchon, R Pitts Crick, Mansoor Sarfarazi

Molecular Ophthalmic Genetics Laboratory, Surgical Research Center, Department of Surgery, University of Connecticut Health Center, 263

Farmington Avenue, Farmington, CT 06030-1110, USA

D Stoilova

T Desai

M Sarfarazi

\section{Department of} Cardiological

Sciences, St George's Hospital Medical

School, London, UK

A Child

G Brice

Department of Ophthalmology, Sainte-Justine Hospital, University of Montreal, Canada M Barsoum-Homsy L Chevrette

\section{Department of}

Ophthalmology,

University of Cukurova

Faculty of Medicine,

Adana, Turkey

N Ozdemir

INSERM U25, Hopital Necker, Paris, France M F Adam

H-J Garchon

\section{International}

Glaucoma Association, King's College Hospital, London, UK

R Pitts Crick

Correspondence to: Dr Sarfarazi.

Received 20 April 1998 Revised version accepted for publication 6 August 1998

\begin{abstract}
Mutations in the trabecular meshwork induced glucocorticoid response protein (TIGR) or myocilin (MYOC) has recently been shown to cause juvenile onset primary open angle glaucoma (JOAG). In this study, we identified two new mutations (Asp380Ala and Ser502Pro) in two British families and another (Pro370Leu) in a French-Canadian family. These mutations were not present in a total of 106 normal chromosomes. In another Turkish family with JOAG, we also detected a sequence variant that was proven to be an amino acid polymorphism (Arg76Lys). No other sequence changes were found in the entire coding region and splice junctions of the TIGR/MYOC gene in this family. However, it is still possible that mutations either in the TIGR promoter or in another neighbouring gene could cause glaucoma in this JOAG family. Our results confirm the role of the TIGR/MYOC gene in the aetiology of the JOAG phenotype. (F Med Genet 1998;35:989-992)
\end{abstract}

Keywords: juvenile onset glaucoma; TIGR/MYOC mutations; locus heterogeneity

Glaucoma is a common ocular neuropathy in which the optic nerve sustains damage in the region of the nerve head, resulting in characteristic changes in the appearance of the optic disc and progressive reduction of visual fields. ${ }^{1} \mathrm{By}$ the year 2000 , an estimated 66.8 million people world wide will be affected with glaucoma, of whom 6.7 million are predicted to become blind. ${ }^{2}$ Juvenile open angle glaucoma (JOAG) is a rare form of glaucoma with an age of onset in childhood or early adulthood. ${ }^{34}$ The intraocular pressures (IOPs) are typically high, frequently above $40 \mathrm{~mm} \mathrm{Hg}$, and pressure lowering surgery is often required to control the progress of the disease. ${ }^{34}$ Positive family history is considered as an important risk factor. JOAG has been documented to segregate in an autosomal dominant fashion with high penetrance. ${ }^{5}$

In 1993 a locus for JOAG was mapped to the 1q21-q31 region and assigned as GLC1A. ${ }^{6}$ Shortly after that, linkage to the GLC1A region was confirmed in additional glaucoma families with different genetic background. ${ }^{78}$ Genetic heterogeneity at the locus has also been established; some reports described linkage to the 1q21-q31 region in families with both JOAG and adult onset POAG. ${ }^{78}$
Recently, mutations in trabecular meshwork induced glucocorticoid response protein (TIGR) (also known as myocilin or MYOC) were identified as a cause of the glaucoma phenotype linked to the GLC1A locus. ${ }^{9}$ TIGR was shown to be expressed in trabecular meshwork, ciliary body, retina, sclera, choroid, and in some extraocular tissues such as mammary gland, thymus, testis, heart, and skeletal muscles. ${ }^{10-13}$ This gene has been implicated to be involved in the pathophysiology of glaucoma by causing obstruction of the aqueous outflow with its product, resulting in an increased intraocular pressure. ${ }^{810}$ More recently, we described a novel mutation (Gln337Arg) in one large JOAG family from Edinburgh, Scotland. ${ }^{14}$ In addition to this, the role of TIGR/MYOC in the aetiology of POAG was confirmed in other families from France, ${ }^{12}$ Japan, ${ }^{15}$ and Germany. ${ }^{16}$

In this report, we describe novel mutations in British and French-Canadian families affected with typical JOAG. We also present a Turkish family with the same condition, which is apparently linked to the 1q21-q31 region, but lacks mutations in any of the coding regions of the TIGR gene.

We studied four Caucasian pedigrees segregating for the JOAG phenotype (fig 1). Two of the families were English (POAG-3 and POAG-31), one was French-Canadian (POAG-501), and another Turkish (POAG801). The glaucoma phenotype was transmitted as an autosomal dominant trait with no apparent skipped generations.

\section{Material and methods}

Blood samples or buccal cells from mouth washes were obtained from all family members who volunteered to participate and DNA was extracted. We used a number of STRP markers flanking the GLC1A locus for PCR amplification. The chromosomal order of these markers, PCR, conditions for electrophoresis, and silver staining have been described previously. ${ }^{14}$ The genotypic data obtained were entered into a dedicated computer program (DMS) and checked for inconsistency. Haplotypes were constructed based on the assumption of a minimal number of recombination events. All four families showed evidence of linkage to the GLC1A region.

After linkage was established to the GLC1A locus, we screened the TIGR gene by single strand conformational polymorphism (SSCP) analysis or by direct sequencing of the PCR products using dRhodamine chemistry and 
Table 1 The TIGR primers and the expected PCR size of 10 overlapping fragments used for SSCP analysis

\begin{tabular}{|c|c|c|c|}
\hline Fragment & Primer name & Primer sequences (5'-3') & $P C R$ size $(b p)$ \\
\hline 1 & $\begin{array}{l}\text { TIGR-Ex1-280F } \\
\text { TIGR-Ex1-545R }\end{array}$ & $\begin{array}{l}\text { CTTTCCAGAGGAAGCCTCAC } \\
\text { GCTGTCTCTCTGTAAGTTATGGAT }\end{array}$ & 266 \\
\hline 2 & $\begin{array}{l}\text { TIGR-Ex1-480F } \\
\text { TIGR-Ex1-744R }\end{array}$ & $\begin{array}{l}\text { AATGAATCCAGCTGCCCA } \\
\text { GGTTGCTGTAGGCAGTCTCC }\end{array}$ & 265 \\
\hline 3 & $\begin{array}{l}\text { TIGR-Ex1-695F } \\
\text { TIGR-Ex1-744R }\end{array}$ & $\begin{array}{l}\text { GGACCAGCTGGAAACCCA } \\
\text { CTGCTGAACTCAGAGTCCCC }\end{array}$ & 258 \\
\hline 4 & $\begin{array}{l}\text { TIGR-Ex2-225F } \\
\text { TIGR-Ex2-449R }\end{array}$ & $\begin{array}{l}\text { TAGTCAATCCTTGGGCCATT } \\
\text { ACCACGTGGGCACAAAAG }\end{array}$ & 225 \\
\hline 5 & $\begin{array}{l}\text { JOAG-3F-2 } \\
\text { JOAG-2R }\end{array}$ & $\begin{array}{l}\text { CCGCATGATCATTGTCTGTGT } \\
\text { ACATCCGTGCCAACTGTGT }\end{array}$ & 204 \\
\hline 6 & $\begin{array}{l}\text { TIGR-Ex3-417F } \\
\text { TIGR-2R }\end{array}$ & $\begin{array}{l}\text { AGACCACGTGGAGAATCGAC } \\
\text { CAATGTCCGTGTAGCCACCC }\end{array}$ & 282 \\
\hline 7 & $\begin{array}{l}\text { TIGR-2F } \\
\text { TIGR-2R }\end{array}$ & $\begin{array}{l}\text { ATACTGCCTAGGCCACTGGAA } \\
\text { CAATGTCCGTGTAGCCACCC }\end{array}$ & 190 \\
\hline 8 & $\begin{array}{l}\text { TIGR-F } \\
\text { TIGR-Ex3-868R }\end{array}$ & $\begin{array}{l}\text { GAGCTGAATACCGAGACAGTG } \\
\text { ACAGATGATGAAGGCATTGGC }\end{array}$ & 256 \\
\hline 9 & $\begin{array}{l}\text { TIGR-1F } \\
\text { TIGR-1R }\end{array}$ & $\begin{array}{l}\text { GAACTCGAACAAACCTGGGAG } \\
\text { CATGCTGCTGTACTTATAGCG }\end{array}$ & 190 \\
\hline 10 & $\begin{array}{l}\text { TIGR-Ex3-944F } \\
\text { JOAG3R }\end{array}$ & $\begin{array}{l}\text { ATCAGCAAGACCCTGACCAT } \\
\text { CCTGAGCATCTCCTTCTGCC }\end{array}$ & 180 \\
\hline
\end{tabular}

an ABI-377 DNA Sequencer, or both. The primers used and the sizes of the resulting 10 overlapping fragments are presented in table 1.

\section{Families}

FAMILY POAG-3

The proband (III.2) is a 29 year old female, diagnosed with open angle glaucoma at the age of 21. Her highest IOPs without treatment were 37 and $47 \mathrm{~mm} \mathrm{Hg}$ in the left and right eyes, respectively. She had severe visual field loss and glaucomatous optic nerve damage. She was also myopic. Her mother (II.1) and grandmother (I.1) were also affected with glaucoma having highly increased IOPs, glaucomatous optic nerve damage, and visual field loss despite intraocular pressure lowering surgery.
SSCP analysis of the TIGR gene in this family detected a shift in the electrophoretic mobility of fragment 8 (table 1). To determine the exact nature of this change, a harbouring fragment was PCR amplified and sequenced. An A1 139C transition was detected that would result in a substitution of aspartic acid (Asp) for alanine (Ala) at amino acid position 380 . The Asp380Ala change was also found in two normal gene carriers. The first subject is a 25 year old male (III.3) who may develop glaucoma in the future. The second person is a 52 year old female (II.3) who is being routinely examined and on her last visit (November 1997) she had IOPs of $16 \mathrm{~mm} \mathrm{Hg}$ in both eyes, cup to disc ratio of 0.2 , and no evidence of any visual field defects. Since she is well past the expected age of onset in this family (range 21 to 35 years), she represents a case of incomplete penetrance.

FAMILY POAG-31

The age of onset in this family ranged between 12 and 33 years, with a mean of 19 years. All the affected members had glaucomatous cupping of the optic discs and gross visual field defects and underwent surgery to control the advancement of the disease.

SSCP analysis of fragment 10 detected a mobility shift suggesting a DNA change that was segregating with the JOAG phenotype in this family (data not shown). Sequencing of PCR product harbouring this fragment showed a T1504C transition that would change serine (Ser) to proline (Pro) at amino acid position 502. One healthy 22 year old male (IV.6) and another 25 year old normal female (IV.9) were also found to carry this mutation. These two
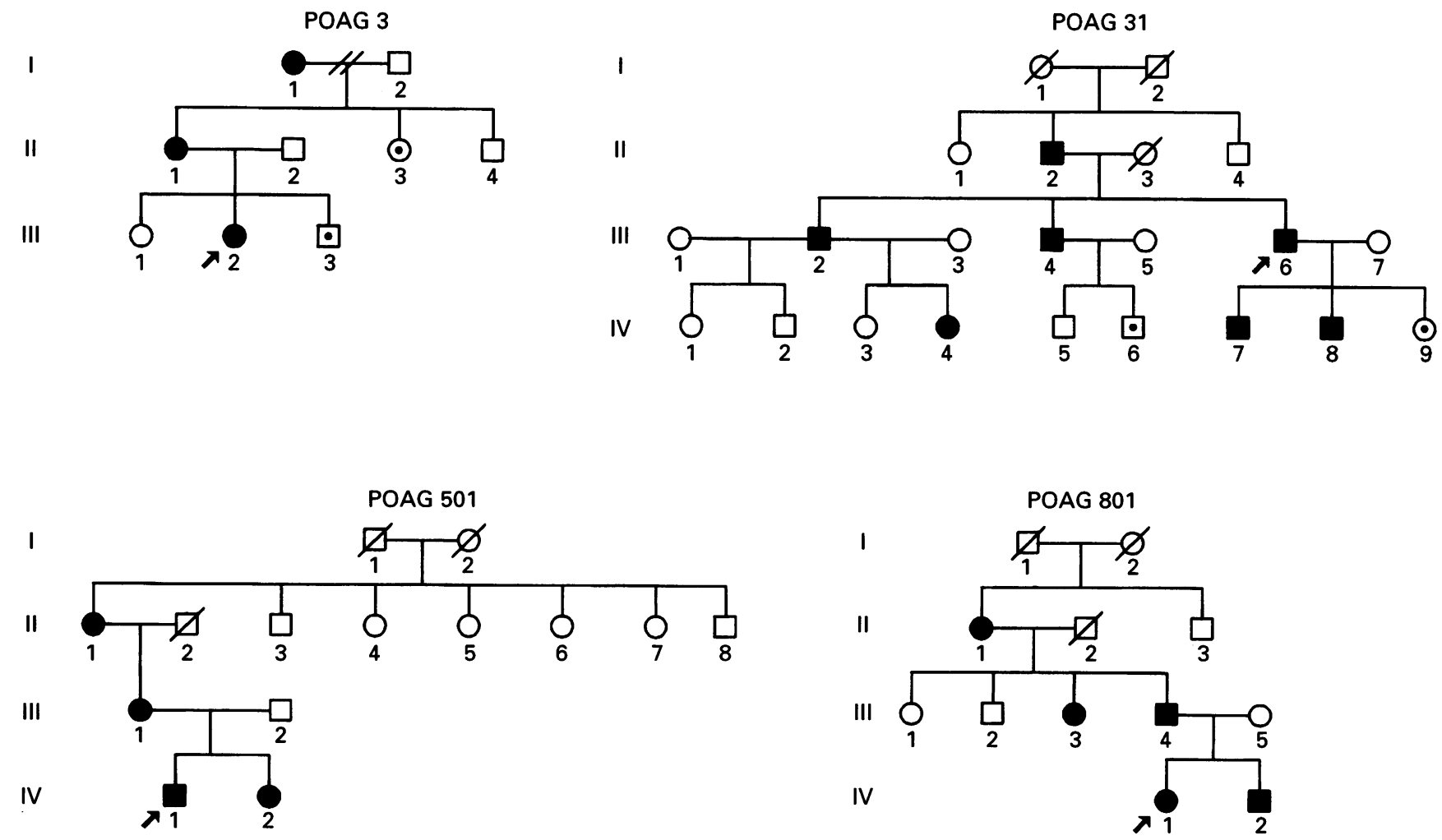

Figure 1 Family structure of the four fOAG families used in this study. 

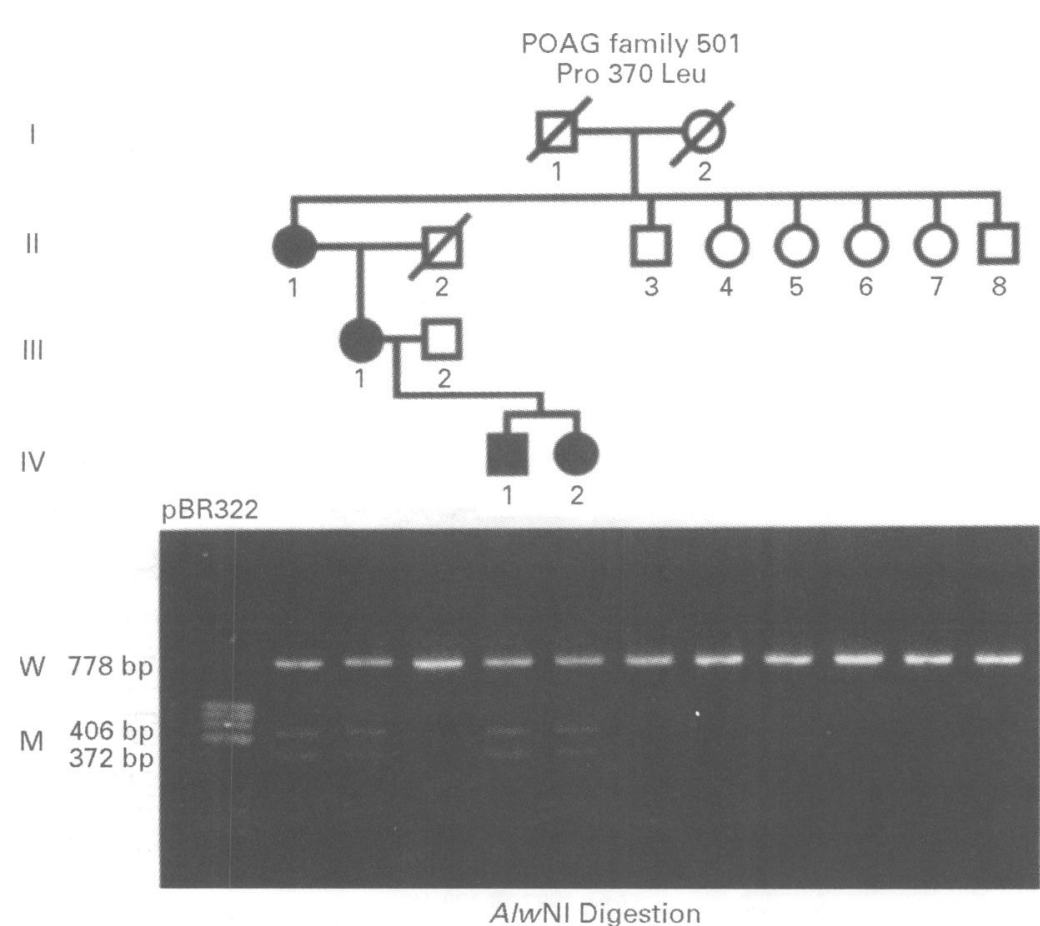

Figure 2 The results of an AlwNI digestion of a PCR fragment that harbours the Pro370Leu mutation in family POAG 501. The resulting mutation has created a new restriction site that after digestion of a PCR fragment of $778 \mathrm{bp}$ would result in two fragments of 406 and $372 \mathrm{bp}$. Note that all the affected subjects carry this restriction site while the unaffected subjects lack it. Notably, person II.3, who carries the affected haplotype (data not shown), does not have this restriction site. The DNA marker used is $p B R 322$ HaeIII digest.
FAMILY POAG-801

The mean age of onset in this pedigree was 21 years. All glaucoma patients had severely raised IOPs ranging between 32 and $44 \mathrm{~mm} \mathrm{Hg}$, gross cupping of the optic nerve discs (cup/disc ratio of $0.9-1.0$ ), and defects in the visual fields. One patient (III.3) has completely lost her vision owing to advanced POAG.

We sequenced the entire coding region, together with the exon/intron boundaries of the TIGR gene using genomic DNA of II.1 as a template. We detected a transition, G227A, that was expected to result in a substitution of arginine for lysine (Arg76Lys). This change deletes a $B s m A I$ restriction site, the segregation of which was further studied in the family (data not shown). Inspection of the haplotypes and analysis of the BsmAI restriction site confirmed the segregation of Arg76Lys with the normal haplotype and showed that this change is indeed an amino acid polymorphism. Despite repeated attempts in this family, no other variants were detected with either SSCP or direct sequencing.

\section{Discussion}

It is now generally accepted that glaucoma encompasses a group of both clinically and genetically heterogeneous disorders resulting from mutations in different single genes or by interaction of multiple genes. Two such genes have already been identified. CYP1B1 (cytochrome P4501B1) was identified as the gene causing primary congenital glaucoma (the GLC3A locus) in the $2 \mathrm{p} 21$ region, ${ }^{18} 19$ and mutations in TIGR have been reported to be responsible for the glaucoma phenotype in POAG families linked to the 1q21-q31 region. $^{8} 91214-17$

The TIGR protein contains a myosin-like domain at the $\mathrm{N}$-terminus and an olfactomedin-like domain in its C-terminus, suggesting that TIGR is an extracellular matrix component possibly involved in protein/protein interactions.$^{8-11}{ }^{13}$ All the mutations reported to date are in the third exon of this gene, corresponding to the olfactomedin domain, which may interfere with the binding activity of the protein. This could result in abnormalities in the uptake or metabolism of the gene product, leading to accumulation of protein and obstruction of the aqueous outflow, which can cause increased IOP and damage to the optic nerve. ${ }^{8}$

In this study, we screened the entire coding region together with the exon/intron boundaries of the TIGR gene for possible mutations in four Caucasian families with typical JOAG. As a result of our investigation, four different amino acid substitutions were detected. Three of them, Pro370Leu, Asp380Ala, and Ser502Pro, are causative mutations in three families, while the Arg76Lys was proven to be an amino acid polymorphism. Two of the mutations observed in this study, Pro370Leu and Asp380Ala, are in the region corresponding to the olfactomedin-like domain; however, Ser502Pro falls outside this region. To the best of our knowledge, both Asp380Ala and Ser502Pro are novel mutations and have not been reported in other families. 
Interestingly, the Pro370Leu substitution that was found in our French-Canadian family was also reported in French, ${ }^{12}$ Japanese, ${ }^{15}$ and German $^{16}$ families. This mutation has occurred in the context of a $\mathrm{CpG}$ dinucleotide and it is more likely to be a recurrent rather than a founder one. Indeed, we provided evidence that the Pro370Leu mutation in our POAG501 family has occurred spontaneously and subsequently passed on in a causative manner to the next two generations (fig 2).

We also presented a Turkish family with a typical JOAG phenotype that lacks any mutations in the entire coding sequence and the intron/exon junctions of the TIGR/MYOC gene. However, it is possible that mutation in the control regions of TIGR or another neighbouring gene accounts for the disease phenotype in this family. Considering the relatively small size of this family, it is also possible that this kindred maps to another region of the genome and, therefore, the observed JOAG phenotype is a phenocopy in this family that is caused by mutation in a gene as yet unknown.

We would like to thank all the participating members of the families presented here. Without their cooperation and willing ness, this study would not have been possible. We are also grateful to a number of other ophthalmologists in the UK and Australia who examined and provided their clinical assessment of the patients for this study. We thank Dr Nurten Akarsu at the DNA/Cell Bank and Gene Research Laboratory, Hacettepe University, Ankara, Turkey for referral of, extraction, and DNA preparation of samples from the Turkish family. This work was supported by grants (all to $M S$ ) from the National Eye Institute (EY-09947), the International Glaucoma Association (IGAG249), the University of Connecticut General Clinical Research Center (M01-RR-06192), and Insite Vision Inc. AC thanks the Bluff thanks the Bluff Field Charitable Trust $\mathrm{UK}$ and the generous support.

1 Shields MB, Ritch R, Krupin T. Classification of the glaucomas. In: Ritch $\mathrm{R}$, Shields $\mathrm{MB}$, Krupin $\mathrm{T}$, eds. The glaucomas. In: Ritch $R$, Shields MB, Krupin T, eds. The
glaus. Louis: Mosby-Year Book Inc, 1996;2:717glaucon.

2 Quigley HA. Number of people with glaucoma worldwide. Br f Ophthalmol 1996;80:389-93.
3 Ellis $\mathrm{OH}$. The etiology, symptomatology and treatment of juvenile glaucoma. Am $\mathcal{F}$ Ophthalmol 1948;31:1589-96.

4 Johnson AT, Drack AV, Kwitek AE, Cannon RI, Stone EM Alward WL. Clinical features and linkage analysis of a fam ily with autosomal dominant juvenile glaucoma. Ophthalmology 1993;100:524-9.

5 Lichter PR. Genetic clues to glaucoma's secrets. The Jackson memorial lecture. Part 2. Am f Ophthalmol 1994;117:706-27.

6 Sheffield VC, Stone EM, Alward WL, et al. Genetic linkage of familial open angle glaucoma to chromosome 1q21-q31. Nat Genet 1993;4:47-50.

7 Raymond V. Molecular genetics of glaucoma: mapping of the first five "GLC" loci. Am ₹ Hum Genet 1997;60:272-7.

8 Sarfarazi M. Recent advances in molecular genetics of glauSarfarazi M. Recent advances in molecula
comas. Hum Mol Genet 1997;6:1667-77.

9 Stone EM, Fingert JH, Alward WLM, et al. Identification of a gene that causes primary open angle glaucoma. Science 1997;275:668-70.

10 Polansky J, Fauss D, Chen P, et al. Cellular pharmacology and molecular biology of the trabecular meshwork inducible glucocorticoid response gene product. Ophthalmologica 1997;211:126-39.

11 Kubota R, Noda S, Wang Y, et al. A novel myosin-like protein (myocilin) expressed in the connecting cilium of the photoreceptor: molecular cloning, tissue expression, and chromosomal mapping. Genomics 1997;41:360-9.

12 Adam MF, Belmouden A, Binisti P, et al. Recurren mutations in a single exon encoding the evolutionarily conmutations in a single exon encoding the evolutionarily conserved olfactomedin-homology domain of TIGR in fam

13 Ortego J, Escribano J, Coca-Prados M. Cloning and characterization of substracted CDNA from human ciliary body including TIGR, a protein involved in juvenile open angle glaucoma and homologous to olfactomedin. FEBS Lett 1997;413:349-53.

14 Stoilova D, Child A, Brice G, Crick RP, Fleck BW, Sarfaraz $M$. Identification of a new 'TIGR' mutation in a family with juvenile-onset primary open angle glaucoma. Ophthal Genet 1997;18:109-18.

15 Suzuki R, Sugihara I, Kurimoto S. Retinal circulation in primary open-angle glaucoma tested by videodensitometric image analysis. Ann Ophthalmol 1992;24:273-7.

16 Michels-Rautenstraus KG, Mardin CY, Budde WM, et al Juvenile open angle glaucoma: fine mapping of the TIGR gene to 1q24.3- q25.2 and mutation analysis. Hum Gene 1998;102:103-6.

17 Belmouden A, Adam MF, Dupont de Dinechi J, et al. Recombinational and physical mapping of the locus for primary open-angle glaucoma (GLC1A) on chromosome 1q23-q25. Genomics 1997;39:348-58.

18 Stoilov I, Akarsu AN, Sarfarazi M. Identification of three different truncating mutations in cytochrome P4501B (CYP1B1) as the principal cause of primary congenital glaucoma (buphthalmos) in families linked to the GLC3A glaucoma (buphthalmos) in families linked to the GLC3A

19 Stoilov I, Akarsu A, Alozie I, et al. Sequence analysis and homology modeling suggest that primary congenital glaucoma on $2 \mathrm{p} 21$ results from mutations disrupting either glaucoma on $2 \mathrm{p} 21$ results from mutations disrupting either cytochrome P450B1. Am 7 Hum Genet 1998;62:573-84. 